\title{
The Barriers to Achieve Financial Protection in Iranian Health System: A Qualitative Study in a Developing Country
}

\author{
Seyran Naghdi ${ }^{*}$, Tayebeh Moradi ${ }^{2}$, Fateh Tavangar ${ }^{3}$, Giti Bahrami ${ }^{3}$, \\ Mohammadi shahboulaghi ${ }^{4}$, Hesam Ghiasvand ${ }^{5}$
}

\section{OPEN ACCESS}

Citation: Seyran Naghdi $^{1}$, Tayebeh Moradi, ${ }^{3}$ Fateh Tavangar, ${ }^{3}$ Giti Bahrami,

${ }^{4}$ Farahnaz Mohammadi shahboulaghi,

${ }^{5}$ Hesam Ghiasvand. J Health

Sci.2017;27(5):491.ddoi:http://

dx.doi.org/10.4314/ejhs.v27i5.7

Received: May 6, 2017

Accepted: May 9, 2017

Published: September 1, 2017

Copyright: ( 2017 Seyran N. This is an open access article distributed under the terms of the Creative Commons Attribution License, which permits unrestricted use, distribution, and reproduction in any medium, provided the original author and source are credited.

Funding: This study was sponsored by Social Determinants of Health Research Center, University of Social Welfare and Rehabilitation Sciences, Tehran, Iran, grant No.: 1334

Competing Interests: The authors

declare that this manuscript was approved by all authors in its formand that no competing interest exists.

Affiliation and Correspondence:

${ }^{1}$ Iran University of Medical Sciences,

Financial Affaires Office,

Department of R\&D, Tehran, Iran

${ }^{2}$ Iran Health Insurance Organization (IHIO), Expert of Health

Services Strategic Purchasing, Tehran, Iran.

${ }^{3} \mathrm{PhD}$. Student of Social Welfare and Health, University of Social

Welfare and Rehabilitation Sciences, Tehran, Iran

${ }^{4}$ Associate Professor, Department of Nursing, University of Social

Welfare and Rehabilitation Sciences, Tehran, Iran

${ }^{5}$ Assistant Professor, Social Determinants of Health Research Center, University of Social Welfare and Rehabilitation Sciences, Tehran, Iran

*Email: hesambs82@gmail.com

\begin{abstract}
BACKGROUND:The move to universal health coverage and consequently health promotion is influenced by political, socioeconomic and other contextual factors in a country. Iran, as a developing country with an upper-middle national income, has developed policies to achieve universal health coverage through financial protection. This study aims to investigate barriers to develop financial protection as a requirement to achieve universal health coverage.

MATERIALS AND METHODS: This qualitative study was conducted using 20 in-depth interviews with experts in social welfare, health insurance and financing. The framework analysis method was used to analyze the data.

RESULTS: The results have been categorized in three major themes that were extracted from ten sub-themes. The major themes included the political, social and economic context of the country, the context and structure of healthcare system and dimensions of $U H C$.

CONCLUSION:Achieving financial protection as a long-term objective should be considered as a priority among Iranian policy makers that requires an inter-sectoral collaboration with a defined in-charge body. Health policy makers in Iran should develop a more comprehensive benefits package for diseases and health conditions with catastrophic consequences. They also should develop a plan to cover the poor people.

KEYWORDS: Universal Health Coverage, Financial Protection, Catastrophic Health Expenditures, Impoverishing Health Expenditures
\end{abstract}

\section{INTRODUCTION}

Ensuring availability, accessibility and affordability of healthcare services has been frequently emphasized as a well-known function of governments. After the release of the World Health Organization (WHO) Report 2000, till now we have witnessed considerable advances in developing plans for population health improvement $(1,2)$. 
Universal Health Coverage (UHC) was introduced by WHO, and several countries initiated their plans to achieve this goal. Receiving high quality and affordable healthcare services in an equitable way and without exposing people to financial hardships is the gist of UHC (3).

Foundations of universal health coverage include redefinition of traditional methods of delivery, financing and control of health system, implementation of comprehensive actions within health systems, and also on political, social and economic factors outside of health system. While developed countries reached UHC, or at least its components such as financial protection, this achievement in some developing countries required reforms in their political and economic structures. These changes took place in some developing countries such as Turkey, Thailand, Chile and China (4).

In Iran, health system is defined using intertwined factors. Currently, in Iran, inpatient (hospital) services are mainly provided by the government, and public sector providers and outpatient services are mainly provided by the private sector. Out-of-pocket payment is the main source of financing and financial contributions of basic health insurance schemes and governmental budgets are about $40 \%(5,6)$. The structure of financing of healthcare services in Iran is presented in Figure 1.

The main part of governmental budget for health in Iran is allocated to primary health care; and money and credits are spent by the Ministry of Health $(\mathrm{MoH})$. Of course the Iranian Health Insurance Organization (IHIO) is contributing in this filed alongside $\mathrm{MoH}$, through Family Physician Plan.
The government has developed some national plans with emphasizing on financial protection. Approving the Public Medical Services Insurance in 1994, the Comprehensive Welfare \&Social Security System Act in 2004 and the $5^{\text {th }}$ National Development Plan in 2011; are some instances(7).

The MoH, in collaboration with Iran Health Insurance Organization (IHIO), has received funds from Iranian annual governmental budget to cover the expenditures of some diseases including cancers, hemophilia, thalassemia, dialysis, MS, joints replacement, epilepsy and Parkinson(8).

Nevertheless, the evidence shows that considerable headcount ratios of catastrophic health expenditures range from $2.1 \%$ to $2.8 \%$ at the national level and from $14.2 \%$ to $22.2 \%$ at the regional level (6). Despite in some other developing countries that have developed protecting policies and plans against catastrophic and impoverishing health expenditures, evidence show some achievements in reducing the occurrence of catastrophic health payments. Turkey, China and Thailand are instances in this regard (9-11).

The WHO believes achieving the UHC without protecting people against financial hardship is impossible (12). Today financial protection is a criteria for assessing the performance of governments (13).

This study aims to investigate barriers to develop financial protection against catastrophic and impoverishing health expenditure as a requirement to achieve universal health coverage in Iran. 
Figure (1): The structure of health care financing in Iran and its main agents

Iranian Health Care Financing Structure

This includes all governmental payments from annual budget to fund the primary health insurance and universal health insurance

\begin{tabular}{|c|c|c|c|c|c|c|c|}
\hline Mir & $\begin{array}{r}\text { y of Cooperati } \\
\text { Welfare ( }\end{array}$ & or \& & & $\begin{array}{l}\text { State } \\
\text { Budget }\end{array}$ & Other & $\begin{array}{l}\text { Private Health } \\
\text { Insurance }\end{array}$ & $\begin{array}{c}\text { Out-of-Pocket } \\
\text { Payments }\end{array}$ \\
\hline 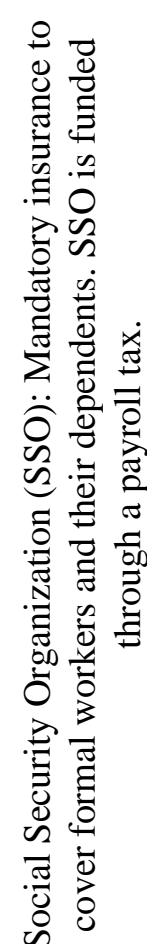 & 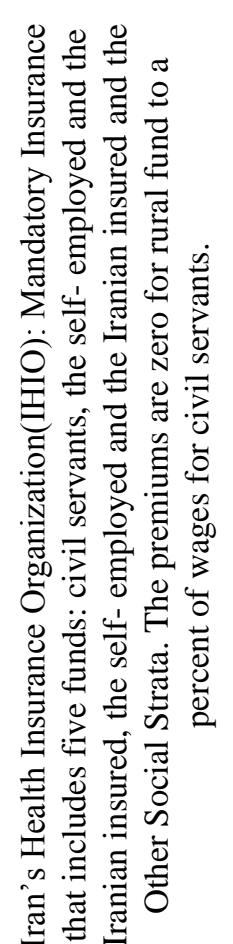 & 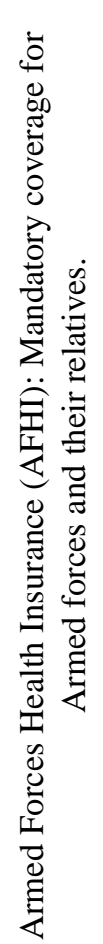 & 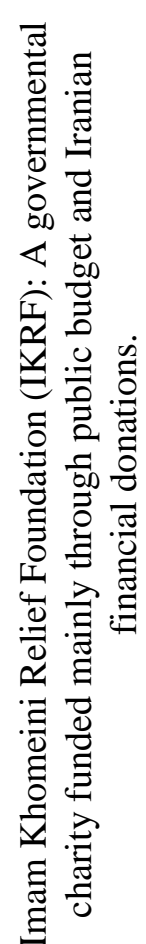 & 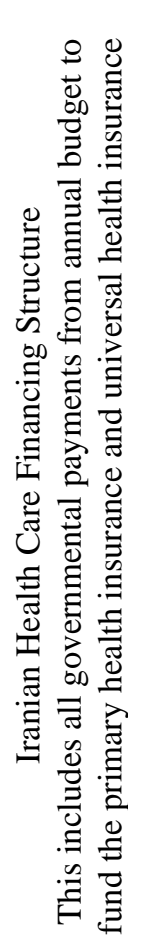 & 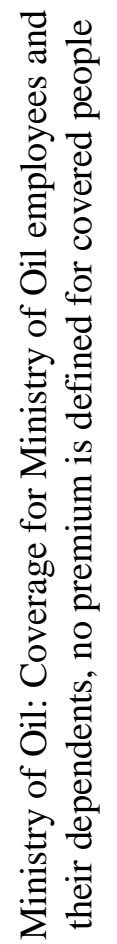 & 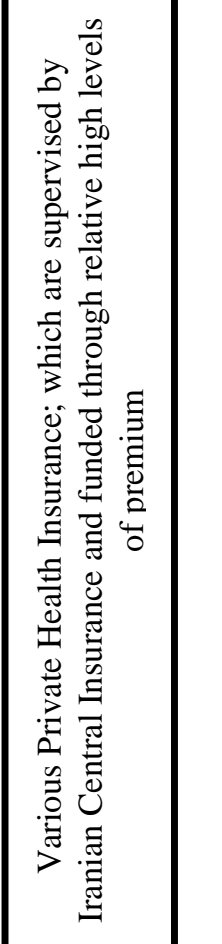 & 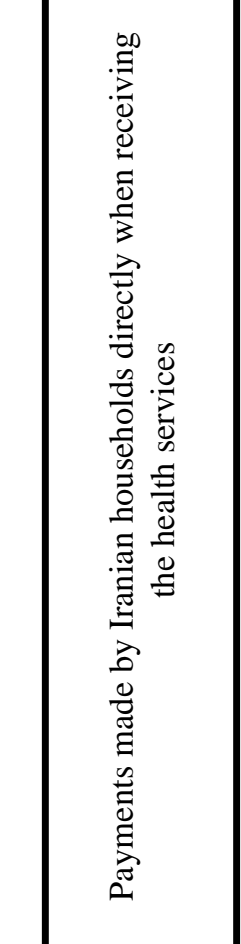 \\
\hline
\end{tabular}


Table (1) presents some key statistics about three basic health insurance organizations in Iran for 2016- 2017

\begin{tabular}{|c|c|c|c|c|c|}
\hline Insurer & No. of Insured & $\begin{array}{c}\text { Annual Budget } \\
\text { (2016- 2017) }\end{array}$ & $\begin{array}{l}\text { Share of } \\
\text { expenditure from } \\
\text { Total Health } \\
\text { Expenditure } \\
\end{array}$ & Method of Calculation of Premium & Liabilities \\
\hline IHIO & $36,000,000$ & $2,795,265,222$ & $9 \%$ & $\begin{array}{l}\text { Iranian Medical Insurance Fund: } 50 \% \text { is paid } \\
\text { by insured and the rest by government, in } \\
\text { case, people which cannot afford the rest of } \\
\text { premium after the confirmation of IKHRF, it } \\
\text { is paid by government. The Rural Fund: No } \\
\text { premium is paid by insured. Civil Servants } \\
\text { Fund: } 5 \% \text { of minimum level of wage and } \\
\text { advantages multiplied by } 2 \text {. Other strata Fund: } \\
\text { the premium depends on the socioeconomic } \\
\text { condition. }\end{array}$ & $\begin{array}{l}90 \% \text { of public approved hospitalized } \\
\text { care in both private and public sectors, } \\
70 \% \text { of public approved out-patient and } \\
\text { ambulatory services in both private and } \\
\text { public sector }\end{array}$ \\
\hline SSO & $40,000,000$ & $4,793,531,620$ & $16 \%$ & $\begin{array}{l}\text { In compulsory insurance coverage, the } \\
\text { premium is defined based on pay-roll tax and } \\
\text { the insured should pay } 7 \% \text {, the employer } 20 \% \\
\text { and the government } 3 \% \text {. }\end{array}$ & $\begin{array}{l}\text { In SSO's own medical center, the } \\
\text { services are free of charge. } \\
\text { Upon purchasing the services from } \\
\text { other private or public providers: } 90 \% \\
\text { of public approved hospitalized care in } \\
\text { both private and public sectors, } 70 \% \text { of } \\
\text { public approved out-patient and } \\
\text { ambulatory services in both private and } \\
\text { public sector }\end{array}$ \\
\hline IKHRF & $4,500,000$ & $30,941,380$ & $1 \%$ & Total premium is paid by government. & $\begin{array}{l}\text { Free of charge for hospitalized services, } \\
\text { special and catastrophic illness. With a } \\
\text { limited franchise for other medical } \\
\text { services }\end{array}$ \\
\hline
\end{tabular}




\section{MATERIALS AND METHODS}

Sampling and data collection: Purposeful sampling, through identifying and gathering data from the experts in social welfare, health care financing and health insurance, was used. The corresponding author was the representative of Iran Medical Council Organization in Iran Supreme Health Insurance Council - the Iranian responsible public body for designing and developing the Iranian health insurance obligations, liabilities in cost-sharing, population coverage and benefit package. Therefore, he communicated with the qualified and informed experts for participating in the study. The inclusion criteria were:

- Having sufficient knowledge and experiences about the financial protection, based on their own statements

- Having motivation to contribute in study

Regarding to report of World Health Organization in 2010 and the World Bank reports

Table (2): The Interviewees' Characteristics about the UHC in developing and low-income country (UHC Comparative Studies Series or UNICO) a semi-structured guide was developed (12). The first author conducted 20 face-to-face interviews until information saturation was reached. The interviews were accomplished from October 2016 to December 2017 in the offices of the participants. The consent forms that were approved by Ethics Committee of funder were filled and signed by interviewees, and except two participants, the rest agreed to record their voices. During the interviews, other informative and relevant notes were taken. The interviewees' characteristics are presented in Table (2).

Data Analysis: A framework analysis conducted to analysis the data.Data was coded and categorized using the framework analysis method. Then, themes and sub-themes (codes) were identified. The corresponding author recruited a postgraduate student to transcribe the recorded voices. Specific codes were dedicated to highlight points and then similar codes were categorized within same themes and were labeled using a defined label.

\begin{tabular}{lccc}
\hline Variables & & Frequency & Percent (\%) \\
\hline Level of Education & M.Sc./MA & 4 & 20 \\
& MD/Dentist/ Specialty & 7 & 35 \\
Educational Field & PhD & 9 & 45 \\
& Medical \& Health Sciences & 16 & 80 \\
& Economic \& Social Sciences & 3 & 15 \\
Organizational & Mathematics & 1 & 5 \\
Position & Technical Officer & 13 & 65 \\
& Head/Manager & 5 & 25 \\
Gender & General Director/Deputy & 2 & 10 \\
& Female & 0 & 0 \\
& Male & 20 & 100 \\
\hline
\end{tabular}

\section{RESULTS}

The time of interviews ranged from 45 to 70 minutes with an average of 50 minutes. Table (3) presents the relationship between categories and themes.
Theme 1: Iranian politicians' and governors' viewpoints about the financial protection: The financial protection as one of the goals of Iran health system has been taken into consideration in national documents of the country. In these documents, the development of financial protection for all Iranian households has been stipulated as one of government obligations.

DOI: http://dx.doi.org/10.4314/ejhs.v27i5.7 
Table (3): Summary of categories and related themes for developing financial protection in Iran

\begin{tabular}{lll}
\hline & Categories(main themes) & \multicolumn{1}{c}{ Themes } \\
\hline & Social, Political \& Economic & The viewpoints of politicians and governors about financial \\
Context of Country & protection \\
& & General political \& economic structure of country \\
& Defining an unified \& central Stewart for financial protection \\
& & The role of NGOs and charities in developing financial \\
& & protection \\
& & Improving health system efficiency for developing financial \\
& Srotection
\end{tabular}

However, it should be noted that national documents in Iran are mainly designed in an idealistic way, and they aim to cover all dimensions of a sector.

One expert in the MoH uttered:

Before writing interesting sentences about the financial protection in our national documents, we seriously need a pragmatic action by our president, ministers of health and social welfare and heads of health insurance organizations. Since the approval of the 3rd Development plan in 2002 we continuously included the reduction in out-of-pocket payment and the development of financial protection in our national plans, but the question is: where we are now?!

Theme 2: General political and economic structure of the country: The financial protection as a goal requires political and economic advocacy by the country's officials. Launching and continuing the financial protection plan depend on the commitments and support from the highest levels of officials of the country. In several developing countries, financial protection has been achieved along with changes in policies and economic reforms and commencement of new governments with a vision of the prosperity of social welfare and health.

One of the officials in the MoH stated:

As a core of the UHC, the financial protection requires a national movement managed by the government. However, in the past, the governments did not facilitate this movement for the financial protection and even in some intervals, they, in turn, were a barriers to achieve the financial protection, because they tried to reduce the funds allocated to health!

Theme 3: Defining a central steward for financial protection: This is another obligation of the government in the field of the development of financial protection. The financial protection requires intersec-toral collaborations, and in Iran, this is one of the challenging aspects of policy making. Capacity building in a sustainable way needs a central authority with the ability to mobilize resources and integrate fragmented efforts into one direction to achieve the UHC.

An expert in the SSO stated:

The financial protection is included in social welfare and here in Iran the 4 basic health insurance schemes, MoH, MCLSW and the Iranian Management and Planning Organization (MPO) are the most relevant public bodies. Each part of these bodies says that this is not their obligation, also there is no law or plan determining a responsible body that other authorities should collaborate with it and obey its policies and plans to reach financial protection.

Theme 4: The role of non-governmental organizations (NGOs) and Charities in

DOI: http://dx.doi.org/10.4314/ejhs.v27i5.7 
developing of financial protection: Achieving financial protection not only depends on intersectoral collaboration between governmental and also non-governmental bodies. In Iran, there are several charities and NGOs playing an active role in identifying, determining entitlement and funding for poor people.

An expert in the MPO believed:

The financial protection is categorized within social welfare affaires which can be reached through the social participation and currently in Iran our society can help the government to achieve it effectively.

A middle level manager in the $\mathrm{MoH}$ stated:

In current situation of country our NGOs and charities cannot integrate with public authorities well, and the financial protection is the responsibility of government, so because of $N G O s$ are not maturate we shouldn't obligate them governmental functions.

Theme 5: Improving health system efficiency for developing the financial protection plan: Although, the adequacy of financial resources may lead to an effective financial protection, the more important point is that we know the source of financing and level of allocated governmental monetary resources to the health. After implementing the Iran Health Transformation Plan (2014), financial resources allocated to the health have increased. Furthermore, implementing reforms to the demand side of the health system such as establishing the strategic purchasing, clinical guidelines, payment mechanisms, referral system and gate keeping will considerably lead to stop wasting of the financial resources.

One of the independent researchers believed:

We cannot stipulate developing financial protection to meet several revising in our general health system! Now our vulnerable and poor populations are deprived from their rights for being healthy. How we can say to them "please wait" because we want to revise the system ...?!

The head of a department in the deputy of social welfare in MCLSW stated:

Since 2002 until now, we have listened to several speeches and seen many texts about improving the control and surveillance role of healthcare services purchasers through establishing strategic purchasing, implementing the family physicians plan and referral system. So far no achievement in this regard has been observed.

Theme 6: The low priority of financial protection for health policy makers: The dominance of dual practice physicians in contexts of influencing organizations such as $\mathrm{MoH}$ as policy makers as well as political pressures by healthcare services providers for what they know it as "realizing of tariffs" have led to a situation that the priorities of Iran's health system have been limited to pricing the therapeutic services.

The head of one department in the AFHI stated that:

When there are clearly conflicts of interests among policy makers, priorities will change and the priority of financial protection will also decrease!

Theme 7: Strengthening control and surveillance roles: Sometimes, catastrophic effects of health services take place because of factors such as providers' induced-demand and also attracting patients from the public sector and transferring the private sector. This happens in, surveillance cannot control this issue effectively.

An expert from IRMCO believed:

Sometimes I hear and see that the medical office of Dr. ... is full of patients with low socioeconomic status, who clearly do not match the medical offices located in the best parts of the city; obviously these patients are forced to borrow, sell their assets or ... in order to afford costs of services.

An expert in the MoH stated:

Unfortunately, we do not have documented evidence about the moral hazard status in the health system of our country, but we can see it and then judge about its occurrence level.

Theme 8: The lack of a comprehensive and integrated information system for developing financial protection: Recent experiences from developing countries indicate the development of financial protection through a bottom-up approach, i.e. the coverage of uninsured population and poor socio-economic groups. This needs developing well-designed information systems, conducting a living standards

DOI: http://dx.doi.org/10.4314/ejhs.v27i5.7 
measurement national survey and determining utilization of the people in focus.

One of the experts in the MCLSW stated:

Her are limitations in developing a national plan for financial protection in Iran due to the lack of a national integrated information platforms focusing on socio- economic and health profiles of people.

Theme 9: The lack of a defined executive plan for covering the poor: After implementing an effective information system, another requirement is to determine an appropriate plan to cover poor. Over the last decades, the poor could not benefit from a national plan. The IKRF is an active public entity in this regard. However, there are still many people whom have not been covered by any governmental supportive scheme.

A top level manager in the $\mathrm{MoH}$ stated:

Although the national laws stipulated a low level of financial contribution by poor per a certain level of services, currently the real poor people have not been covered by governmental schemes effectively.

Theme 10: Disproportionate developing if UHC and its components in Iran: The UHC includes three related dimensions: cost- sharing, benefits package and population coverage. Each of these three dimensions can decrease or increase the level of financial protection, and the experiences of other countries indicate creating a balance in developing each of the three dimensions. In Iran, the population coverage, especially after the HTP, was developed rapidly. On the other hand, the benefits package in Iran is generous. In contrast, cost-sharing is very low and Out-of-Pocket has main contribution in financing.

An expert in the IHIO pointed out:

Each of two major health insurance schemes, IHIO and SSO, cover about half of Iranian population, and after implementing the HTP, almost 10,000,000 uninsured people were also covered! So, now we should not have any uncovered person in the country, but in

Although the $\mathrm{MoH}$ in Iran established an office to collect donations from charities and the people, this office is mainly active in attracting financial reality, there are a considerable number of people without health insurance.

\section{DISCUSSION}

Developing financial protection in Iran has been faced with some barriers including the political, economic and social context of the country; health system pitfalls alongside the disproportionate extension of the UHC dimensions. At national level, the legislators have considered financial protection repeatedly in formal documents, but in the executing phase, the governments did not fulfill their functions. This has been found in other studies about the UHC and financing in Iran $(14,15)$

Previous and current economic challenges in the country such as decreasing rate of economic growth, increasing rate of unemployment, international sanctions against Iran and domestic mismanagement imposed constraints on governments to develop the financial protection in Iran. The adverse effects of these constraints would be managed by governments especially in the health system. Otherwise, during economic growth and prosperity periods, there are less challenges against financial protection $(16,17)$.

As mentioned, the financial protection is an intersectoral concept that requires a constructive collaboration between public institutions and nonpublic bodies. This type of plan may face some challenges in a developing country such as Iran (18). The experiences of other countries such as China, Turkey and Mexico demonstrated the positive impact of identified governor to financial protection successfulness (19-21).

Under the current economic constraints in Iran, the governments can benefit from the capacity of NGOs and charities in developing financial protection. Of course, some believe that NGOs in Iran are not prepared to be assigned for accomplishing the governmental functions such asfinancial protection. The Iranian government may use their capacities in identifying the poor and monitoring the accessibility of services.

contributions from people and charities for constructions and investments such as building hospitals and equipping them with beds,

DOI: http://dx.doi.org/10.4314/ejhs.v27i5.7 
equipment and technologies, not for the financial protection. Such plans with the features mentioned have been developed and implemented in China, Turkey, Thailand and Chile (22).

One of the aspects of capacity building to financial protection is related to mobilizing the financial resources. Some studies concluded that we need reforms on the demand side of health services and mainly focus on the prevention of wasting resources to develop effective financial protection scheme $(23,24)$.

The low priority of financial protection among health policy makers is another barrier which should be addressed. Some studies concluded that over the last years the main concern of the Iranian health system players was about the treatment and modernization of medical centers (14).

Failure in establishing a comprehensive information system is another barrier to achieve financial protection. The government does not have integrated information about the Iranian health and socio-economic profiles. Currently, in Iran, there are databases for registering information on some socio-economic measures. These fragmented patterns of information require to be unified in order to make a greater information system that can be utilized for financial protection objectives( 22,25$)$.

The real poor have not been included in financial protection scheme and one of the main challenges for government refers to this. These related to: Lack of national information system, second the weakness of current tools to classifying the people according to their real economic conditions. Such policies have been developed in Turkey through social support for poor and then integrated it in "Health Transformation Plan"(20).

Regarding the cube of UHC and associated dimensions, now in Iran, the population coverage is extended considerably, although marginalized and slum parts of society have not been covered yet. The benefit package is generous. However, about the cost-sharing, the burdens of costs are imposed to healthcare users through out-ofpocket $(23,26)$.

The government of Iran should target the financial protection as one of the core aspects of social welfare and security in a pragmatic approach. This requires political and economic commitments and defined policies plus strategic and executive plans with assigned functions for each authority. The intersectoral identity of financial protection needs specific responsible public bodies to develop the policies, plans and get the collaboration of other bodies.

Limitations:We could not find well-informed, experienced and willing female participants. One female was well- informed about the financial protection in the country, she was a middle-level manager in one of the basic health insurance organizations. She was not willing to be interviewed. Generally, the context of the health system organizations in Iran, specially pertaining to the health insurance, is related to last decade and most of the technical experts and managers are male.Based on experiences of corresponding author, the female may have contrast ideas about developing financial protection in Iran. They may believe that we need more efficient and effective managing of current financial resources and controlling mechanisms.

\section{ACKNOWLEDGEMENTS}

The authors gratefully acknowledge the experts, managers and researchers who were interviewed and contributed to this study. We also acknowledge anonymous reviewers for their insightful comments.

\section{REFERENCES}

1. Jacobs B, Ir P, Bigdeli M, Annear PL, Van Damme W. Addressing access barriers to health services: an analytical framework for selecting appropriate interventions in low-income Asian countries. Health Policy Plan. 2012;27(4):288-300.

2. Kullgren JT, McLaughlin CG, Mitra N, Armstrong K. Nonfinancial barriers and access to care for US adults. Health Serv Res.2012;47(1pt2):462-85.

3. Kieny M-P, Evans DB. Universal health coverage. East Mediterr Health J. 2013;19(4):305-306.

4. Cotlear D, Nagpal S, Smith O, Tandon A, Cortez R. Going universal: how 24 developing countries are implementing universal health coverage from the bottom up: World Bank Publications; 2015.Available:

https://openknowledge.worldbank.org/bitstream/ha ndle/10986/22011/9781464806100.pdf?sequence= 4\&isAllowed=y.

5. Zakeri M, Olyaeemanesh A, Zanganeh M, Kazemian M, Rashidian A, Abouhalaj M, et al.

DOI: http://dx.doi.org/10.4314/ejhs.v27i5.7 
The financing of the health system in the Islamic Republic of Iran: A National Health Account (NHA) approach. Med J Islam Repub Iran. 2015;29:243.

6. Ghiasvand H, Gorji HA, Maleki M, Hadian M. Catastrophic Health Expenditure Among Iranian Rural and Urban Households, 2013-2014. Iran Red Crescent Med J. 2015;17(9):1- 11.

7. Law on the Comprehensive Welfare and Social Security Organizational Structure [Internet]. Islamic republic of Iran Consultative Assembly (Majlis). 2017 [cited 08/11/2016]. Available from: http://www.ilo.org/dyn/natlex/natlex4.detail?p_lan $\mathrm{g}=$ en \&p_isn=91516\&p_country=IRN\&p_count $=1$ 68.

8. Islamic Republic of Iran Health Insurance Organization; liabilities and medical services commitments [Internet]. Islamic Republic of Iran Health Insurance Organization. 2017 [cited 01/12/2017]. Available from: http://ihio.gov.ir/portal/Home/Default.aspx?Catego ryID=ef707e96-09be-4b09-ad55-c6d6e5d34e6a.

9. Yardim MS, Cilingiroglu N, Yardim N. Catastrophic health expenditure and impoverishment in Turkey. Health policy. 2010;94(1):26-33.

10. Li Y, Wu Q, Liu C, Kang Z, Xie X, Yin H, et al. Catastrophic health expenditure and rural household impoverishment in China: what role does the new cooperative health insurance scheme play? PLoS One. 2014;9(4):e93253.

11. Somkotra T, Lagrada LP. Which households are at risk of catastrophic health spending: experience in Thailand after universal coverage. Health Aff. 2009;28(3):w467-w78.

12. WHO. The world health report; health systems financing: the path to universal coverage. Geneva,Switzerland: World Health Organization; 2010.

13. Boerma T, Eozenou P, Evans D, Evans T, Kieny M-P, Wagstaff A. Monitoring progress towards universal health coverage at country and global levels. PLoS medicine. 2014;11(9):e1001731.

14. Ibrahimipour H, Maleki M-R, Brown R, Gohari M, Karimi I, Dehnavieh R. A qualitative study of the difficulties in reaching sustainable universal health insurance coverage in Iran. Health policy plan. 2011;26(6):485-95.

15. Ramezanian M, Abolhalaj M, Bastani P, Hashemi S, Hamidi H. Islamic Republic of Iran Health System Financing: Weak and Strength Points with a Qualitative Attitude. World J Medic Sci. 2013;8(3):231-7.
16. Savedoff WD, de Ferranti D, Smith AL, Fan V. Political and economic aspects of the transition to universal health coverage. The Lancet. 2012;380(9845):924-32.

17. Hosseini SA. Impact of sanctions on procurement of medicine and medical devices in Iran; a technical response. Arch Iran Med. 2013;16(12):736-738.

18. Khayatzadeh-Mahani A, Fotaki M, Harvey G. Priority setting and implementation in a centralized health system: a case study of Kerman province in Iran. Health policy plan. 2013;28(5):480-94.

19. Liang L, Langenbrunner J. The long march to universal coverage: lessons from China: World Bank Washington DC; 2013. https://openknowledge.worldbank.org/bitstream/ha ndle/10986/13303/74960.pdf?sequence $=1$ \&isAllo wed $=y$.

20. Menon R, Mollahaliloglu S, Postolovska I. Toward universal coverage: Turkey's green card program for the poor: World Bank Washington, DC; 2013. https://openknowledge.worldbank.org/bitstream/ha ndle/10986/13309/75012.pdf?sequence=1 \&isAllo wed $=y$.

21. Frenk J, Sepúlveda J, Gómez-Dantés O, Knaul F. Evidence-based health policy: three generations of reform in Mexico. The Lancet. 2003;362(9396):1667-71.

22. Tangcharoensathien $\mathrm{V}$, Limwattananon $\mathrm{S}$, Patcharanarumol W, Thammatacharee J. Monitoring and evaluating progress towards universal health coverage in Thailand. PLoS Med. 2014;11(9):e1001726.

23. Davari M, Haycox A, Walley T. The Iranian health insurance system; past experiences, present challenges and future strategies. Iran JPublic Health. 2012;41(9):1.

24. Davari M, Haycox A, Walley T. Health care financing in iran; is privatization a good solution? Iran J Public Health. 2012;41(7):14.

25. Bazyar M, Rashidian A, Kane S, Mahdavi MRV, Sari AA, Doshmangir L. Policy options to reduce fragmentation in the pooling of health insurance funds in Iran. Int J Health Policy Manag. 2016;5(4):253.

26. Mousavi SM, Sadeghifar J. Universal health coverage in Iran. Lancet Glob Health. 2016;4(5):e305-e6. 